\title{
Formulation and In-vitro Evaluation of Itraconazole Floating Microparticles
}

Taha A. Basher",1 and Entidhar J. Al-Akkam*

*Department of Pharmaceutics, College of Pharmacy, University of Baghdad, Baghdad, Iraq.

\begin{abstract}
Itraconazole (ITZ) is an antifungal drug (BCSII) used for the treatment of local and systemic fungal infections. Furthermore, ITZ used as an antifungal prophylaxis for immunocompromised patients.

The objective of the study is to overcome the two problems of low and pH dependent solubility of ITZ by its preparation as floating microparticles.

Firstly, pH-dependent floating microparticles were prepared using oil in water solvent evaporation method, from which the best one (F7) selected as a best pH-dependent formula with composition of ITZ (200mg),EC (800mg), HPMC 15cps (200mg) and safflower oil (2ml) .Then, F7 was compared with the selected Relatively pHindependent ITZ floating microparticles formula with composition of ITZ(200mg), a first coat of HPMC15cps (200mg), a second coat of EC (800mg), HPMC 15cps (200mg) and safflower oil (2ml) which prepared by a dual coating solvent evaporation method using a first coat which provides relatively $\mathrm{pH}$-independent solubility, while the second coat applied as a bouncy producing agents. Polyvinyl alcohol (PVA) was used as a surfactant in both cases.
\end{abstract}

The prepared floating microparticles were subjected to various evaluation parameters such as yield percent, drug loading and drug entrapment efficiency (EE), particle size analysis, in-vitro bouncy, drug release, Fourier Transforms Infrared Spectroscopy (FTIR), Differential Scanning Calorimetry (DSC) and X-ray Diffractometry (XRD) studies.

The selected relatively $\mathrm{pH}$-independent formula (F16) has a particle size of $11.29 \mu \mathrm{m}$ with a polydispersity index of 0.651 , and the best $\mathrm{pH}$-dependent formula (F7) has a particle size of $2.56 \mu \mathrm{m}$ with PDI of 0.37. In vitro drug release per cent from the selected formula (F16) was $100 \%$ at 10 hour (pH 1.2) while was $84 \%$ at 12 hour ( $\mathrm{pH} 1.2)$ for $\mathrm{F} 7(\mathrm{p}>0.05), 62 \%$ at 12 hour $(\mathrm{pH} 3.7)$ for formula (F16) while was $22 \%$ at 12 hour $(\mathrm{pH} 3.7)$ for F7 (p < 0.05), was $35 \%$ at 12 hour ( $\mathrm{pH}$ 6.8) from F16while, $7 \%$ at 12 hour (pH 6.8) from F7(p< $0.05)$. Therefore ITZ release from the selected formula (F16)is significantly better(p $<0.05)$ and the bouncy per cent of selected formula (F16) was $95 \%$ that was significantly better than bouncy percent of F7 that was $86 \%$ ( p $<0.05$ ) in formula 16 . InF7, \%DL and \%EE were $97 \%$ and $89 \%$, respectively, while in F16 both \%DL and \%EE were $96 \%$.

FTIR results showed no change in the peaks of the ITZ microparticles functional group while XRD and DSC show change the physical state of ITZ which indicate conversion from crystalline to amorphous, which had better stability(F16).

Thus, dual-coated floating microparticles (F16) appeared to be a promising approach to improve solubility at different $\mathrm{pH}$ values and prolong the release of the ITZ within the stomach that may increase its oral bioavailability.

Keywords: Itraconazole, Hydroxypropylmethylcellulose 15cps, Eudragits S100, solvent evaporation method, microparticles
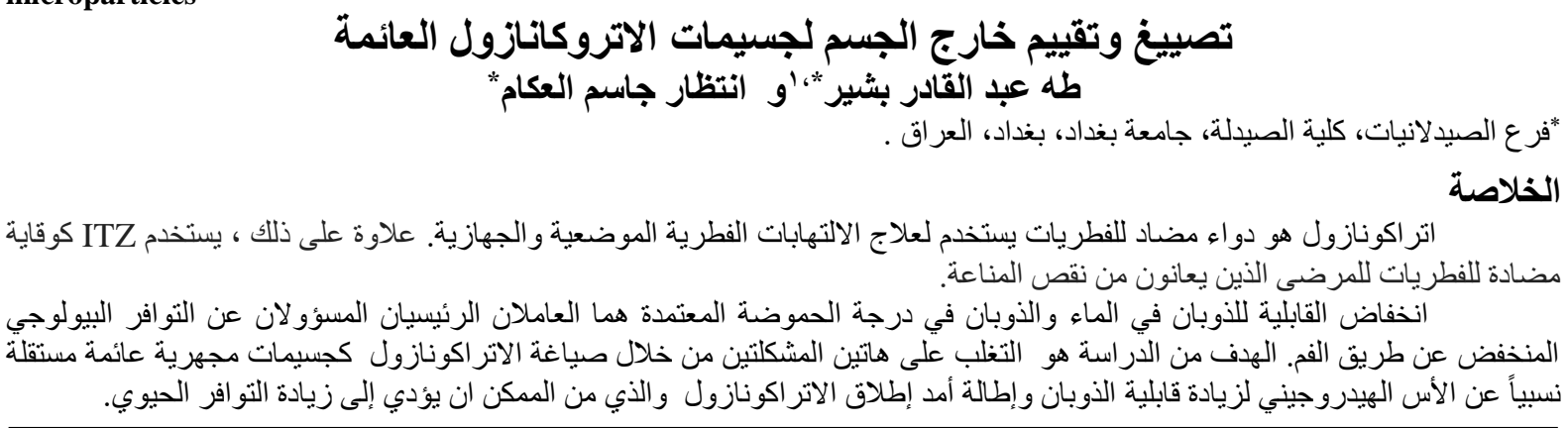

${ }^{1}$ Corresponding author E-mail: babantaha497@yahoo.com

Received: 23/11/2019

Accepted: 25/1/2020

Iraqi Journal of Pharmaceutical Science 


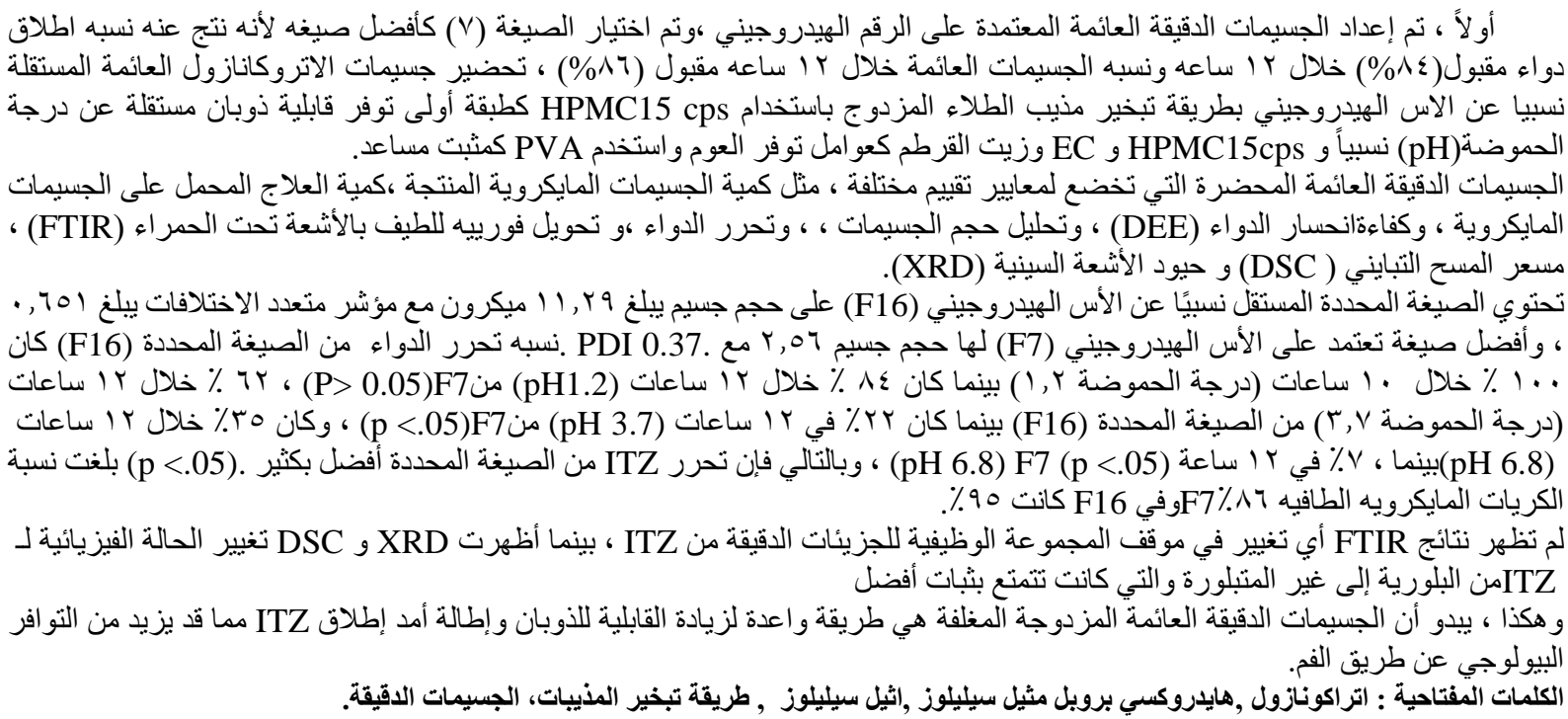

\section{Introduction}

Oral drug administration is the most common route to get a systemic effect due to its numerous advantages like safety, noninvasive, painless, does not require assistance, more convenient for chronic drugs administration and the medicament not need to be sterile.(1)However, several factors can affect the oral bioavailability, including water solubility and $\mathrm{pH}$-dependent solubility. Hence, several techniques have been used to overcome these challenges include a reduction of the particle size that solves just water solubility problem(not the $\mathrm{pH}$-dependent problem) such as micronisation or nanonisation, use of surfactants and conversion of crystalline to amorphous forms ${ }^{(2)}$.

Oil in water solvent evaporation method is most straight forward method for microencapsulation, widely used in pharmaceutical industries and costeffective. This directly modified technique can be used to overcome many drugs physicochemical problems including both water solubility and $\mathrm{pH}$ dependent solubility using specific coating materials (3). Microparticles defined as solid particles with range of 1 and $1000 \mu \mathrm{m}$ in diameter consisting of a core (drug) and coat layer prepared using one of the microencapsulation methods to overcome core (drug) related undesired physicochemical properties to obtain a_more therapeutically effective $\operatorname{drug}^{(4)}$.

Itraconazole is an active triazole, antifungal agent $\left(\mathrm{C}_{35} \mathrm{H}_{38} \mathrm{Cl}_{2} \mathrm{~N}_{8} \mathrm{O}_{4}\right)$, which is active against a broad spectrum of fungal species including Cryptococcus, Candida, Aspergillus, Blastomyces and Histoplasma capsulatum. ${ }^{(5,6)}$

Itraconazole is (BCS II) and has a pKa of $3.7^{(7)}$. ITZ has the characteristic of $\mathrm{pH}$-dependent solubility having the highest solubility at the acidic media $(4 \mu \mathrm{g} / \mathrm{ml})$ compared to basic $\mathrm{pH}(1 \mu \mathrm{g} / \mathrm{ml})$. It is slightly soluble in alcohols and freely soluble in dichloromethane and practically insoluble in water (8), indicating that low aqueous solubility and $\mathrm{pH}$ dependent solubility are the main reasons for low oral bioavailability. Itraconazole is a weak basic drug with $\mathrm{Pka}$ of (3.7), therefore at a low $\mathrm{pH}$, of gastric juice, ITZ will be ionised therefore, the gastric acidity is essential for adequate dissolution, and its oral bioavailability increased when taken with food since gastric $\mathrm{pH}$ decrease after food intake ${ }^{(9)}$.However, Firstly the $\mathrm{pH}$ of the stomach is variable and impossible to remain below 1.2 value, secondly there are cases that raise stomach $\mathrm{pH}$ value thus lead to decrease of ITZ solubility, and therefore bioavailability include fasting state, patients taking gastric acid-reducing agents such as protein pump inhibitors(PPI) and H2-blockers and Furthermore patients with AIDS who complain from Hypochlorhydria. ${ }^{(10)}$.

The objective of this study is to overcome both low water solubility and $\mathrm{pH}$-dependent solubility of Itraconazole by formulating it as floating microparticles and one with a relatively $\mathrm{pH}$ independent floating microparticles and compared between them thus to improve the solubility at variable $\mathrm{pH}$ values and prolong the release of the ITZ in stomach, which may lead to increase in ITZ bioavailability.

\section{Materials and Methods \\ Materials}

Itraconazole (ITZ) powder (Baji Gaokang BioTechnology Co., Ltd., China), Hydroxy propylmethylcellulose (HPMC15cps)(Shanghai Ruizheng chemical Tech Co., Ltd., China),Ethylcellulose (EC)(BDH Chemical Ltd., England),Extra virgin olive oil (EVOO), Rice bran oil (RBO), Palm oil (PO) and safflower oil (SFO) (Furkan Dogalurunler.TIC.SAN.LTD, Turkey). Dichloromethane (DCM) (Thomas Baker Chemicals PVT.Ltd., India), Ethanol, methanol and n-hexane (Chem-LabNV.,Belgium). Hydrochloric acid (HCL) (Central Drug House (P) Ltd., India). Eudragit S100 (ED S100) (ATHOS CHEMICALS, Co., Ltd., India).

\section{Methods}

Saturation solubility determination

Solubility studies for the pure drug achieved in $0.1 \mathrm{~N}$ $\mathrm{HCl}(\mathrm{pH} 1.2), \mathrm{HCl}$ buffer ( $\mathrm{pH} 3.7)$ and phosphate buffer ( $\mathrm{pH}$ 6.8) alone and with SLS at a concentration of 2,3 and $6 \%(\mathrm{w} / \mathrm{v})$, respectively. 
Excess amount of pure ITZ was added to $10 \mathrm{ml}$ of each solution in a test tube and agitated at $25 \pm 0.5^{\circ} \mathrm{C}$ in a rotary test tube shaker for $72 \mathrm{hr}$. Then, samples were filtered using $0.45 \mu \mathrm{m}$ Millipore filters. Each filtrate suitably was diluted with the respective solvent and analyzed by measuring the absorbance at the determined maximum wavelength $\left(\lambda_{\max }\right)$ in each solvent usingUV-1800 UV-Vis Spectrophotometer (Shimadzu Scientific Instruments Inc., Japan). The solubility $(\mathrm{mg} / \mathrm{ml})$ of ITZ was calculated ${ }^{(11)}$.

Preparation of ITZ floating microparticles (pHdependent)

Oil in water solvent evaporation method was used to prepare floating microparticles $(\mathrm{pH}$ dependent) of ITZ. Fifteen formulas prepared using different concentrations of polymers including; EC,HPMC 15cps and ED S100. Different oils were also used such as; Extravirigin olive oil (EVOO), Rice bran oil (RBO), palm oil (PO) and safflower oil (SFO). Polyvinyl alcohol (PVA) was used as a surfactant, as shown in table (1).

The vegetable oils were not used in formulas F1-F3. The used oils dissolved in a vehicle composed of (DCM) and ethanol at 1:1 ratio forming the oil phase to which the drug added. While the aqueous phase containing $0.75 \%$ PVA as a surfactant. The oil phase was added to the aqueous phase drop wise using a bared syringe, under highspeed mechanical agitation of 1000rpm by utilizing magnetic stirrer for one hour at $25 \pm 1^{\circ} \mathrm{C}$ to allow the organic solvent to evaporate and get the microparticles that filtered and dried at room temp overnight. Each formula was washed with $5 \mathrm{ml}$ DCM to remove the excess oil if needed and dried again $^{(12)}$.

Table 1.Composition of ITZ floating microparticles (pH-Dependent)

\begin{tabular}{|c|c|c|c|c|c|c|c|c|c|c|c|c|c|c|c|}
\hline \multirow[t]{2}{*}{ Ingredient } & \multicolumn{15}{|c|}{ Formula no. } \\
\hline & F1 & F2 & F3 & F4 & F5 & F6 & F7 & F8 & F9 & F10 & F11 & F12 & F13 & F14 & F15 \\
\hline ITZ(mg) & 200 & 200 & 200 & 200 & 200 & 200 & 200 & 200 & 200 & 300 & 200 & 200 & 200 & 200 & 200 \\
\hline$\overline{\mathrm{EC}(\mathrm{mg})}$ & 900 & 800 & 700 & 800 & 800 & 800 & 800 & 700 & 900 & 800 & 800 & 800 & - & 800 & 800 \\
\hline $\begin{array}{l}\text { HPMC15 } \\
\text { CPS(mg) }\end{array}$ & 100 & 200 & 300 & 200 & 200 & 200 & 200 & 300 & 100 & 200 & 200 & 200 & 200 & 200 & 200 \\
\hline $\begin{array}{l}\text { EDS100 } \\
(\mathrm{mg})\end{array}$ & & & & & & & & & & & & & 800 & & \\
\hline $\begin{array}{l}\text { EVOO } \\
(\mathrm{ml})\end{array}$ & & & & 2 & & & & & & & & & & & \\
\hline $\begin{array}{l}\text { RBO } \\
(\mathrm{ml})\end{array}$ & & & & & 2 & & & & & & & & & & \\
\hline $\mathrm{PO}(\mathrm{ml})$ & & & & & & 2 & & & & & & & & & \\
\hline $\mathrm{SFO}(\mathrm{ml})$ & & & & & & & 2 & 2 & 2 & 2 & 1 & 2 & 2 & 2 & 2 \\
\hline $\begin{array}{l}\text { Ethanol } \\
(\mathrm{ml})\end{array}$ & 20 & 20 & 20 & 20 & 20 & 20 & 20 & 20 & 20 & 20 & 20 & 20 & 20 & 20 & \\
\hline $\begin{array}{l}\text { Methanol } \\
(\mathrm{ml})\end{array}$ & & & & & & & & & & & & & & & 20 \\
\hline DCM (ml) & 20 & 20 & 20 & 20 & 20 & 20 & 20 & 20 & 20 & 20 & 20 & 20 & 20 & 20 & 20 \\
\hline $\mathrm{DW}(\mathrm{ml})$ & 400 & 400 & 400 & 400 & 400 & 400 & 400 & 400 & 400 & 400 & 400 & 200 & 400 & 400 & 400 \\
\hline $\mathrm{PVA}(\%)$ & 0.75 & 0.75 & 0.75 & 0.75 & 0.75 & 0.75 & 0.75 & 0.75 & 0.75 & 0.75 & 0.75 & 0.75 & 0.75 & 0.75 & 0.75 \\
\hline Speed(rpm) & 1000 & 1000 & 1000 & 1000 & 1000 & 1000 & 1000 & 1000 & 1000 & 1000 & 1000 & 1000 & 1000 & 500 & 1000 \\
\hline
\end{tabular}


Preparation of relatively $\mathrm{pH}$-independent ITZ floating microparticles

Dual coating solvent evaporation method used for the development of the relatively $\mathrm{pH}$ independent ITZ floating microparticles. The first coat composed of HPMC $15 \mathrm{cps}$. It was applied by using oil in water solvent evaporation method then without filtration the second coat was an organic solution of HPMC15, EC and SFO in 1:1 of DCM: ethanol as a solvent ${ }^{(13)}$ as represented in table 2 .

Table2. Composition of ITZ relatively pHindependent floating microparticles

\begin{tabular}{|c|c|c|}
\hline Ingredient & \multicolumn{2}{|l|}{ F 16} \\
\hline \multirow[t]{2}{*}{ ITZ (mg) } & \multicolumn{2}{|c|}{200} \\
\hline & $1^{\text {st }}$ coat & $2^{\text {nd }}$ coat \\
\hline HPMC15 CPS (mg & 200 & \\
\hline DCM (ml) & 10 & \\
\hline Ethanol (ml) & 10 & \\
\hline $\mathrm{EC}(\mathrm{mg})$ & & 800 \\
\hline HPMC15 CPS (mg) & & 200 \\
\hline SFO (ml) & & 2 \\
\hline Ethanol (ml) & & 20 \\
\hline $\mathrm{DCM}(\mathrm{ml})$ & & 20 \\
\hline DW (ml) & 400 & \\
\hline Speed (rpm) & 1000 & 1000 \\
\hline
\end{tabular}

Characterization of the prepared floating microparticles

\section{Percentage yield determination}

Yield of the prepared microparticles calculated by dividing the dry weight of the prepared microparticles (practical weight) by the total weight of the drug and excipients used (theoretical weight) as stated in the following equation:

Yield $(\%)=$

(Actual weight/theoretical weight) $\times 100$

Particle size and polydispersity index (PDI) determination

All of the prepared formulations were in the micro size that is bellow $212 \mu \mathrm{m}$ because all are sieved using sieve number 70 . In addition , particle size and PDI of the prepared ITZ floating microparticles F7,F12, F14,F15 and F16 measured by dynamic light scattering (DLS) using Nano Brook 90Plus particle size analyzer (Brookhaven instruments. the USA). Measurements were performed in triplicate by measuring the intensity of light scattered by the molecules in the sample as a function of time at $90^{\circ}$ scattering angle and constant temperature $25{ }^{\circ} \mathrm{C}$. The PDI was determined, which measured the width of the size distribution of each formula; it is an index of spread or variation within the particle size ${ }^{(14)}$.

Drug loading and entrapment efficiency (EE) determination

$25 \mathrm{mg}$ of each formula dissolved in $50 \mathrm{ml}$ methanol. The solution filtered by $0.45 \mu \mathrm{m}$ Millipore filters and $1 \mathrm{ml}$ was taken and diluted with methanol if required. The samples were analyzed for drug content spectrophotometricaly at $262 \mathrm{~nm}^{(14)}$.

$\mathrm{EE}(\%)=($ Actual drug loading $/$ theoretical drug loading) $\times 100$

Drug loading $(\%)=($ Actual drug content $/$ Weight of powdered microsphere) $\times 100$ (3)

\section{Buoyancy per cent determination}

Weight of the formula equivalent to $100 \mathrm{mg}$ ITZ was spread over the test media using dissolution apparatus (type II) that filled with $900 \mathrm{ml}$ of $0.1 \mathrm{~N} \mathrm{HCl}(\mathrm{pH} \mathrm{1.2}, \mathrm{pH} 3.7)$ and phosphate buffer (pH 6.8) separately in each case. The medium was agitated with a paddle rotating at $50 \mathrm{rpm}$ for $12 \mathrm{~h}$. both floating time (FT) and floating lag time were calculated. The floating and the settled portions of microspheres recovered separately were dried and weighed. All the bouncy studies were performed in duplicate ${ }^{(14)}$ Bouncy $\%=(\mathrm{Wf} / \mathrm{Wf}+\mathrm{Ws}) \times 100$

\section{In- vitro release studies}

All formulations were subjected to invitro release studies. The studies were carried out by USP apparatus II (paddle method) at $50 \mathrm{rpm}$ using $900 \mathrm{ml}$ of $0.1 \mathrm{~N} \mathrm{HCL} \mathrm{(pH} \mathrm{1.2,} \mathrm{pH}$ 3.7) and phosphate buffer $(\mathrm{pH}$ 6.8). The temperature maintained at $37 \pm 0.5^{\circ} \mathrm{C}$. At specific time intervals (every two hours), five $\mathrm{ml}$ aliquots were withdrawn and analyzed by UV spectrophotometer at the respective $\lambda_{\max }$ after suitable dilution against suitable blank. The removed volume replaced with an equal volume of fresh solvent ${ }^{(9)}$. All release studies performed in duplicate. ${ }^{(14)}$

\section{Differential scanning calorimetry (DSC)}

The DSC of pure ITZ powder and selected formula (F16) was taken on (Shimadzu DSC-60 plus, Japan).Ten milligrams sealed in the flatbottomed aluminum pan of the differential scanning calorimeter. Data collection was achieved at a temperature range of $25-200^{\circ} \mathrm{C}$ and the heating rate was $5^{\circ} \mathrm{C} / \mathrm{min}$ under nitrogen gas at a flow rate of $25 \mathrm{ml} / \mathrm{min}^{(15)}$.

Fourier transform infrared spectroscopy (FTIR) analysis

The FTIR spectra of pure ITZ and selected formula were recorded using FTIR -7600, 
Australia spectrophotometer. Powders were mixed with potassium bromide and compressed into disks using hydraulic press before scanning from 4000 to $400 \mathrm{~cm}^{-1}(16)$.

\section{$X$-ray powder diffractometry study}

The XRD patterns for pure ITZ and selected formula (F16) were analyzed using an XRD6000, Shimadzu-Japan. The sample chosen scanning was conducted over powder X-ray diffractometer at the axis of 2 thetas, with the continuous scan range of 5-80 degree. The operating voltage was $40 \mathrm{kV}$ and current $30 \mathrm{~mA}$ and scans step size of $0.050^{\circ}(2 \theta)$ and scan step time of 60 seconds ${ }^{(17)}$.

\section{Statistical analysis}

To investigate the significance of the difference between the results of studied formulations, T-test used. The level of significance set at a $\alpha 0.05$, and $(\mathrm{P}<0.05)$ was considered to be statistically significant.

\section{Results and Discussion}

\section{Saturation solubility of pure ITZ}

The saturated solubility of ITZ were $0.1,0.01$ and 0.0044 in $0.1 \mathrm{~N} \mathrm{HCl}(\mathrm{pH} 1.2)$, HCL buffer (pH3.7) and phosphate buffer for ( $\mathrm{pH}$ 6.8), respectively as shown in Fig (1). Since Sodium lauryl sulfate (SLS) is a surfactant, so it used to increase the solubility of ITZ to fulfill sink condition. The saturated solubility of ITZ were $0.42,0.37$ and 0.36 at $0.1 \mathrm{~N} \mathrm{HCl}(\mathrm{pH} 1.2$ with $2 \%$ SLS), (pH3.7with3\% SLS) and phosphate buffer of $\mathrm{pH} 6.8$ with $6 \%$ SLS.

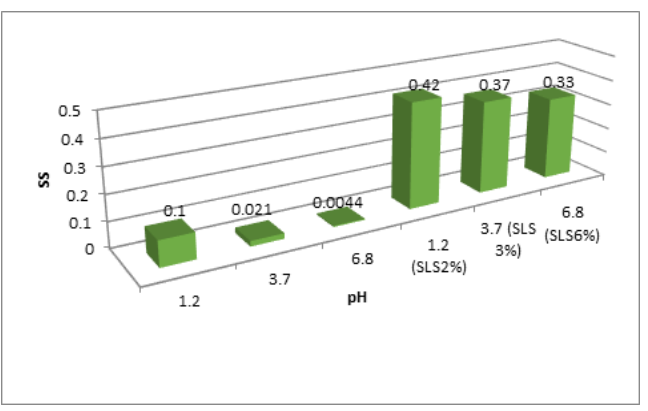

\section{Figure 1. Saturated solubility of pure ITZ at} different $\mathbf{p H}$.

\section{Percentage yield}

The yield per cent of various floating microparticles formulas prepared depicted in figure (2).Per cent yield does not reach $100 \%$ usually due to mechanical variables during preparation method and precipitation of the formula components on the tools used in the preparation. The percent yield was $58 \%$ in F2 were no vegetable oils used. However, the use of vegetable oils results in significant increase in yield per cent, F4 98\%, F5 95\%, and F6 91\%, F7 $86 \%$ were different vegetable oils used ( $\mathrm{p}<$ .05). Also, the higher SFO volume (F7 two $\mathrm{ml}$ versus one $\mathrm{ml}$ in $\mathrm{F} 11$ ) result in the higher per cent yield ( F7 92\% and F11 88\%) may be due to the higher oleic acid content when higher volume used. In F16, the lower yield was due to the longer stirring time that is three hours compared to one hour in F7 (different method was used). ${ }^{(18)}$

Similarly, the lower HPMC15 cps concentration results in a higher yield per cent, in F8 were 300mg of HPMC and $700 \mathrm{mg}$ of EC the yield was $83 \%$ while in F9 were $100 \mathrm{mg}$ of HPMC and $900 \mathrm{mg}$ of EC used a yield of $98 \%$. This result may be due to increasing HPMC $15 \mathrm{cps}$ concentration result in a higher viscosity of the oil phase which results in flocculation and agglomeration of the prepared microparticles thus lower yield per cent. Nepal et al. had found that the higher polymer concentration, the higher yield percent until an certain value after which the yield decreased ${ }^{(12)}$.

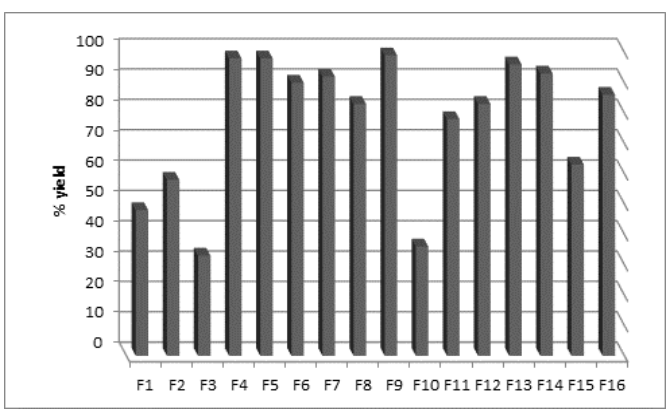

Figure 2. Percentage yield of ITZ floating microparticles.

\section{Particle size analysis}

All the prepared formulations were in the micro size bellow $212 \mu \mathrm{m}$ because all are sieved using sieve number 70. However, F7, F12, F14, F15 and F16_particle size determined using, dynamic light scattering (DLS) by Nano Brook 90Plus particle size analyzer, and their particle size varied from $2.56 \mu \mathrm{m}$ to $6.086 \mu \mathrm{m}$ as shown in figure 3.the higher stirring rate; the smaller microparticles size due to less tendency of the formed microparticles to coalescence and aggregate ${ }^{(18,19)}$. Regarding the (F16), the particle size is bigger due to the higher drug-topolymer ratio and the longer stirring time ${ }^{(20)}$.

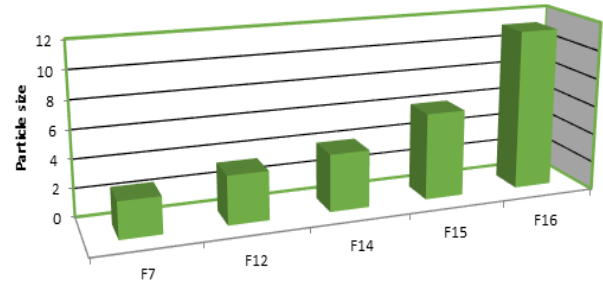

Figure 3. Particle size $(\mu \mathrm{m})$ of ITZ floating microparticles 
Drug loading and entrapment efficiency (EE) determination

The results of drug loading (DL) and drug entrapment efficiency (EE) have been shown in figure (4) and figure (5), respectively. InF4, F5, F6, F7, the \%DL was 98, 98, 92 and $97 \%$, respectively, and \%EE was $98,97,84$ and $89 \%$, respectively while in F1, F2 and F3 the \%DL was range from 50-79 and \%EE range from 2046.Using vegetable oils results in a significant increase in both drug loading and entrapment +efficiency $(p<0.05)$. Vegetable oil with higher oleic acid content results in higher DL and EE (F4). Similarly, these parameters increase upon using of lower concentration of HPMC15cps; in F8 were $300 \mathrm{mg}$ of HPMC15cps used, \%DL was 86 , and EE was 71 while in F9 were $100 \mathrm{mg}$ of HPMC15cps used \%DL was 99 and \%EE was 98.The preparation technique dual coating solvent evaporation method also results in higher DL and $\mathrm{EE}^{(21)}$.

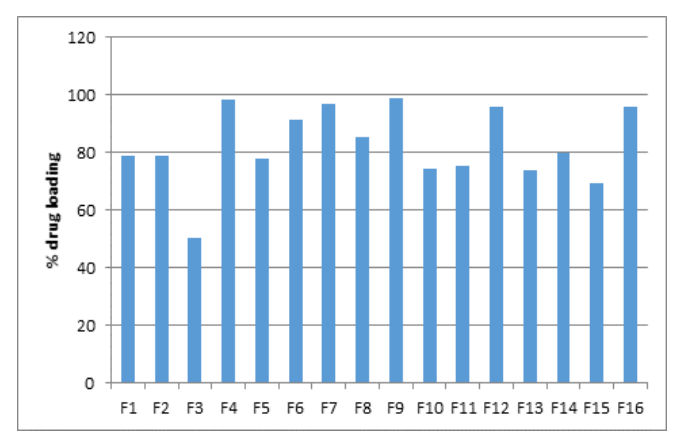

Figure 4. Drug loading of ITZ floating microparticles

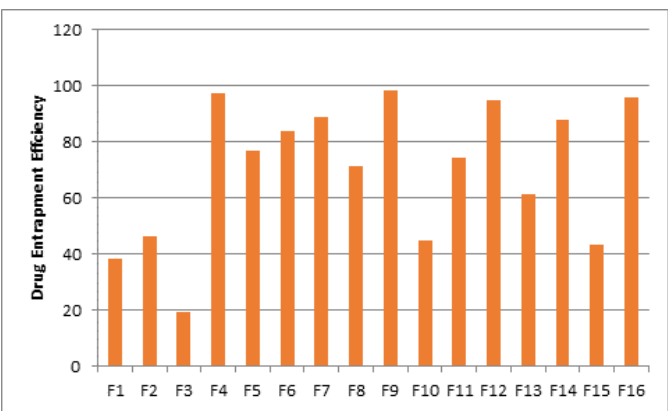

Figure 5. Entrapment efficiency of ITZ floating microparticles.

\section{Buoyancy percent}

The floating lag time (FLT) was zero for all formulas since floating has occurred immediately after the formula spread over the test media $\left({ }^{23)}\right.$. The floating time (FT) was range from $3 \%$ ( F3) to $98 \%(\mathrm{~F} 4)$ as shown in Fig (6).Vegetable oils used were the key factor that provides bouncy; with higher oleic acid content of the vegetable oil; higher bouncy per cent obtained so in (F4) EVOO used that had the highest oleic acid content among the used vegetable oil resulting highest bouncy per cent
(94\%). Also, the concentration of HPMC15cps played an essential role in the determination of bouncy per cent with the lower the HPMC14cps concentration, the higher bouncy per cent $(95 \%$ in F9). Floating ability result from the low density of the prepared microparticles . Similar results observed with floating microparticles of resperidone ${ }^{(12)}$.

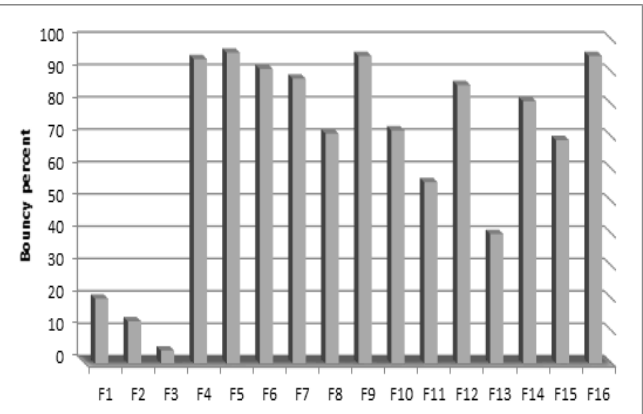

Figure 6. Bouncy percent of ITZ floating microparticles

In vitro drug release

In vitro cumulative release per cent from the selected formula (F16) was $100 \%$ at 10 hour $(\mathrm{pH} 1.2)$ while was $84 \%$ at 12 hour $(\mathrm{pH} 1.2)$ from F7 ( $>>0.05$ ), $62 \%$ at 12 hour ( $\mathrm{pH} 3.7$ ) from selected formula(F16) while was $22 \%$ at 12 hour ( $\mathrm{pH} 3.7)$ from $\mathrm{F} 7(\mathrm{p}<0.05)$, was 35 $\%$ at 12 hour ( $\mathrm{pH} 6.8)$ while, $7 \%$ at 12 hour $(\mathrm{pH}$ 6.8) from $\mathrm{F} 7(\mathrm{p}<0.05)$, therefore ITZ release from the selected formula is significantly better(p < 0.05)as shown in figures (7) and (8). These results indicated the efficiency of the dual coating solvent evaporation method and the $\mathrm{pH}$-independent polymers used in solving the problem of the $\mathrm{pH}$-dependent release of Itraconazole. Furthermore, since, Itraconazole is BSCII drug thus decreasing the particle size to micro-scale resulted in higher solubility this coordinated with Noyes-Whitney equation, in which the dissolution rate enhanced as the saturation solubility increased and the particle size decreased .Also, relatively $\mathrm{pH}$-independent solubility advantage resulted from the first coat, namely HPMC $15 \mathrm{cps}^{(13,22,23)}$.

Another factor that may contribute to the fast release was the entrapment efficiency which had a direct effect on the drug release profile. As it increased, the release rate also increased (24). 


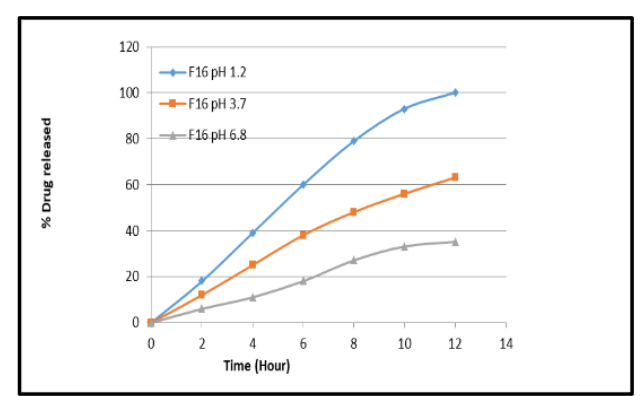

Figure 7. Release profile for $\mathbf{p H}$-dependent ITZ floating microparticles at various $\mathrm{pH}$.

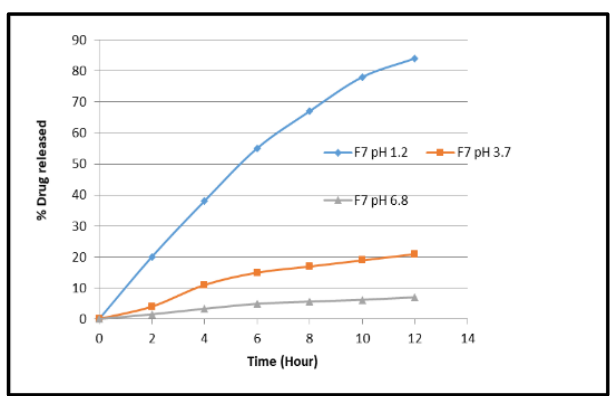

Figure 8. Release profile for relatively $\mathrm{pH}$ independent ITZ floating microparticles at various $\mathbf{p H}$.

Differential scanning calorimetry (DSC)

The DSC was used to estimate the effect of excipients and conditions on the physical properties of the drug. Pure ITZ exhibited a sharp endothermic melting peak at $170^{\circ}$ (Figure 9) indicating no change in its melting temperature and the drug had a crystalline nature with high purity. The DSC of the selected formula (F16) in figure 10 showed the complete disappearance of the melting peak of ITZ gave clear evidence of the transformation of the drug from crystalline to the amorphous state $^{(25,26)}$.

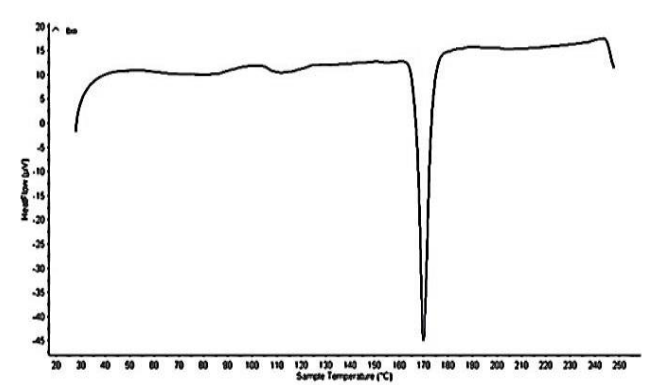

Figure 9. DSC thermogram of pure ITZ at temperature range $\left(20-250{ }^{\circ} \mathrm{C}\right)$

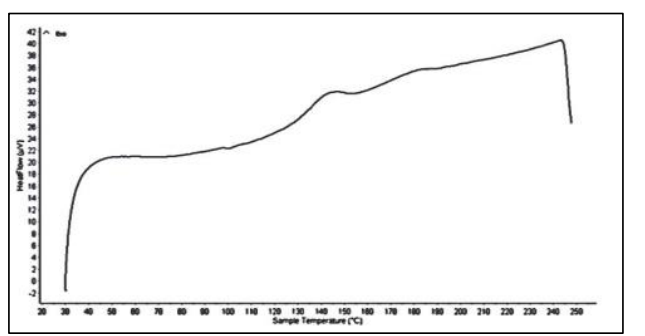

Figure 10. DSC thermogram of selected formula (16) at temperature range $(20-250$ $\left.{ }^{\circ} \mathrm{C}\right)$

\section{Fourier transforms infrared spectroscopy (FTIR)}

The FTIR spectrum of pure ITZ shown in figure 11. The main peaks of pure ITZ observed at wavenumbers,3466, 3130, 2965, $3067,1698,2822,1611,1512$ and $1453 \mathrm{~cm}^{-1}$. It should be noted that all the characteristic bands of ITZ were detected in the spectrum of the physical mixture of drug, EC, HPMC $15 \mathrm{cps}$, as shown in figure 12. Therefore, there is no interaction between the drug and polymers used. A sharp band at $1698 \mathrm{~cm}^{-1}$ in the pure drug spectrum was due to $\mathrm{C}=\mathrm{O}$, in the FTIR spectrum of the selected formula (F16) all of the ITZ characteristic peaks are present as shown in figure 13 excepted that, the peak 1698 that shifted to 1745 this is because the fatty acids content of safflower oil has a characteristic peak at 1745 that shown in figure $14^{(27)}$ thus, in conclusion, the drug, polymers and safflower oil used in the formulation were compatible with each other. ${ }^{(28,29)}$.

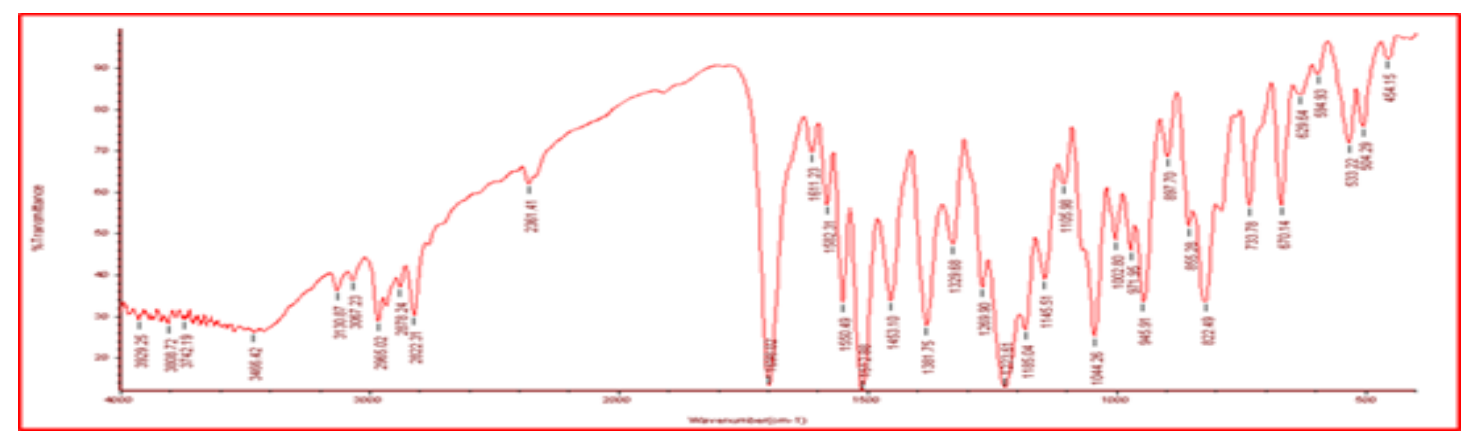

Figure 11. FTIR spectrum of pure ITZ. 


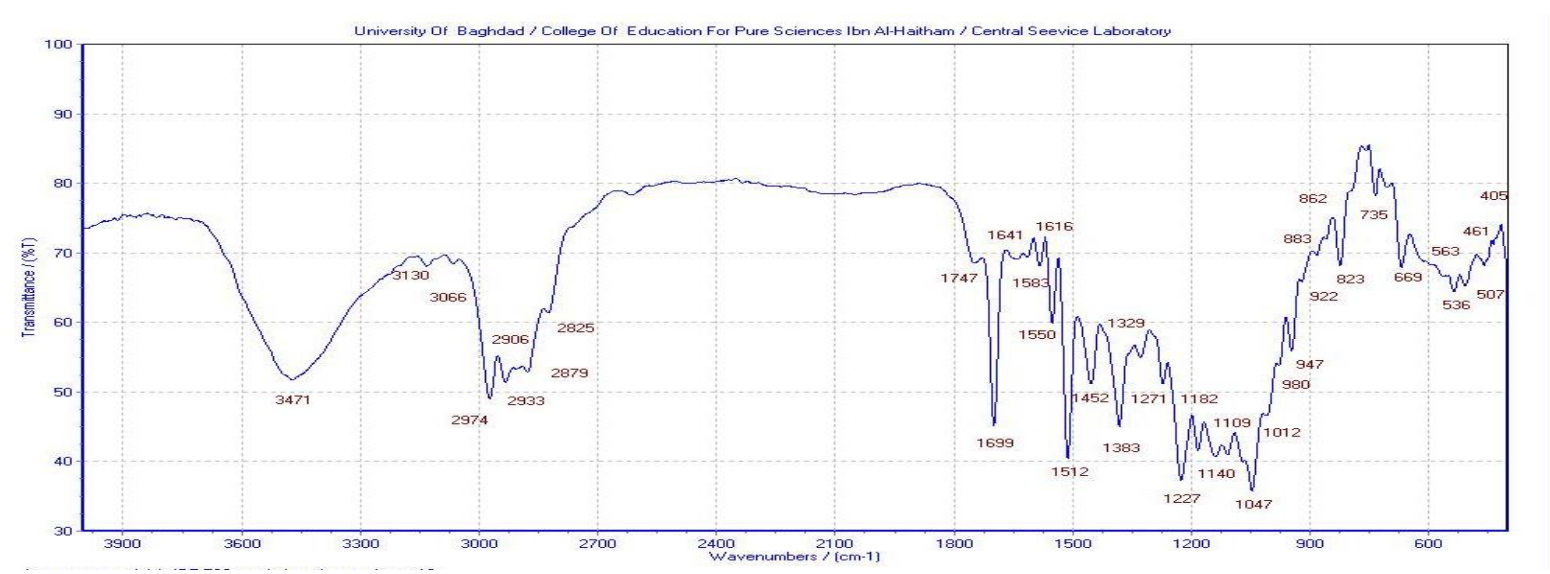

Figure 12. FTIR spectrum of the physical mixture of drug, EC and HPMC 15cps.

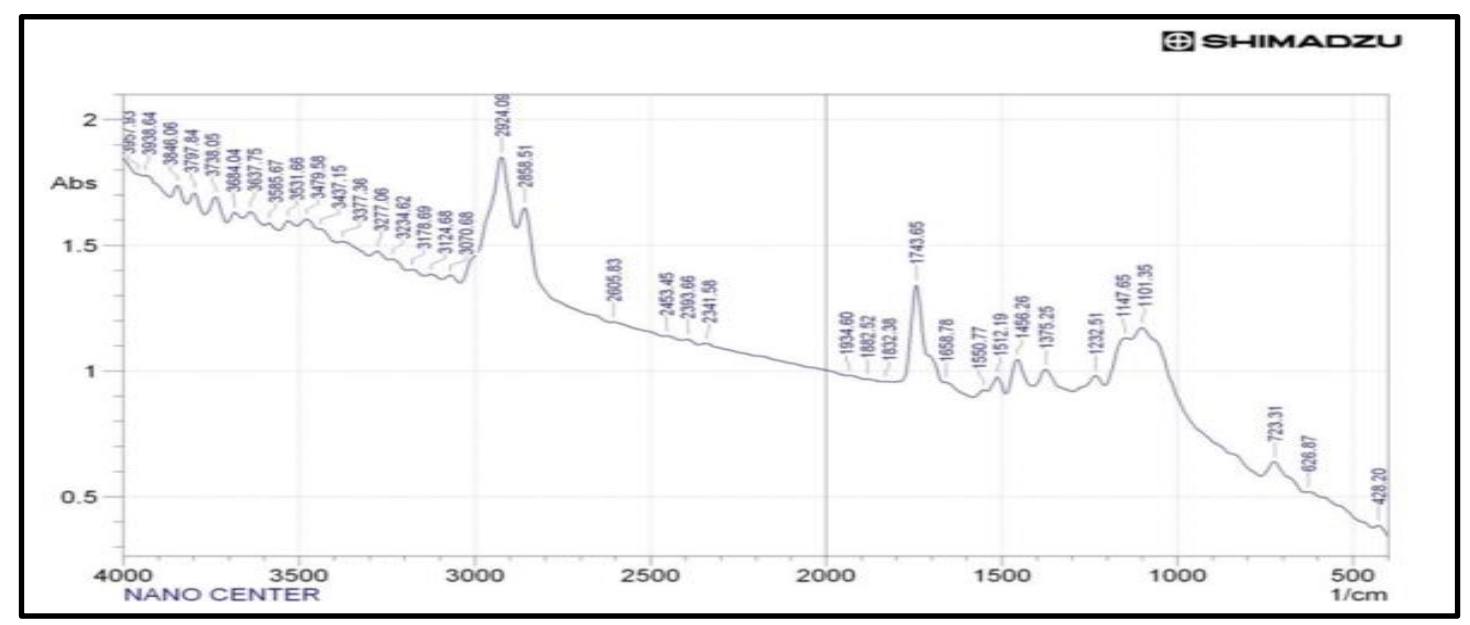

Figure13.FTIR spectrum of floating microparticles (selected formula F16)

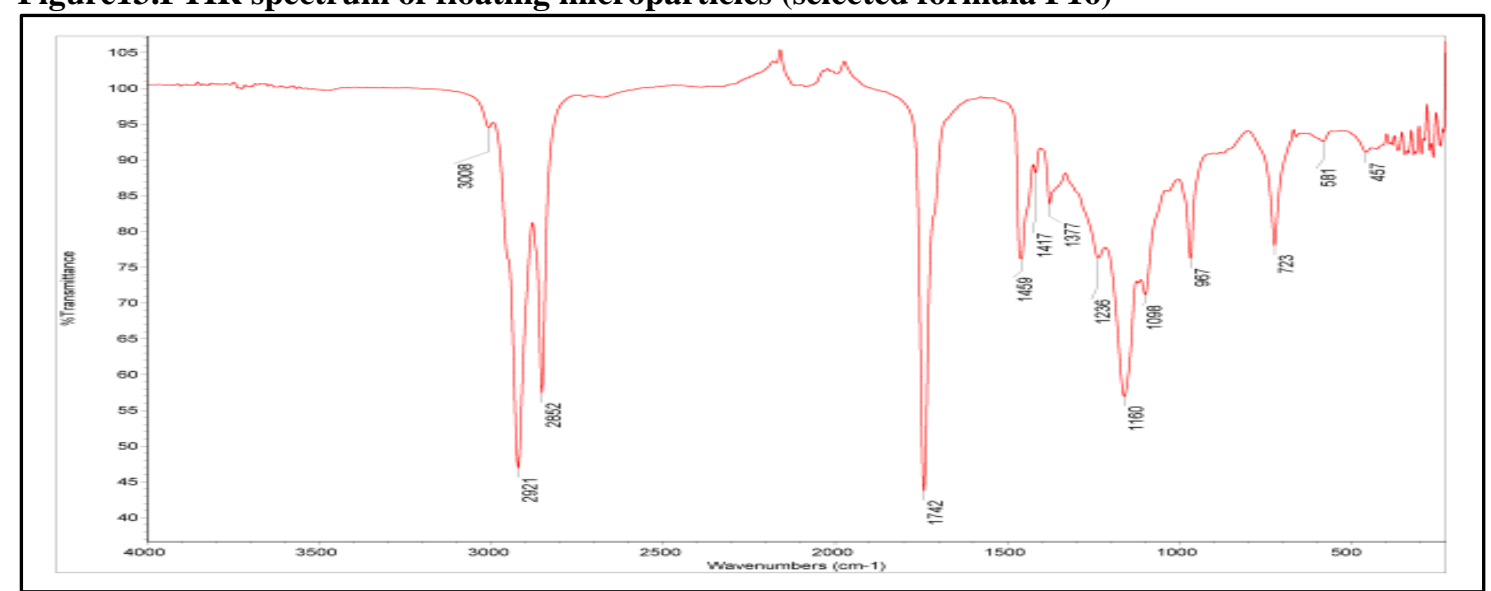

Figure 14. FTIR spectrum of safflower oil. ${ }^{(27)}$

\section{Powder X-ray diffraction (PXRD)}

XRD test of the pure drug and the selected formula (F16) was done to detect the polymorphic structure of the drug before and after formulation. Generally, the amorphous mater sate has higher physical stability. Crystalline nature of pure ITZ easily detected through the numerous distinctive peaks as shown in figure $15^{(27)}$. The XRD of F7 and F16 showed disappearance of the characteristic peaks of pure ITZ as shown in figure 16 and 17 indicated that ITZ incorporated into the polymer matrix that was in the amorphous state (30). 


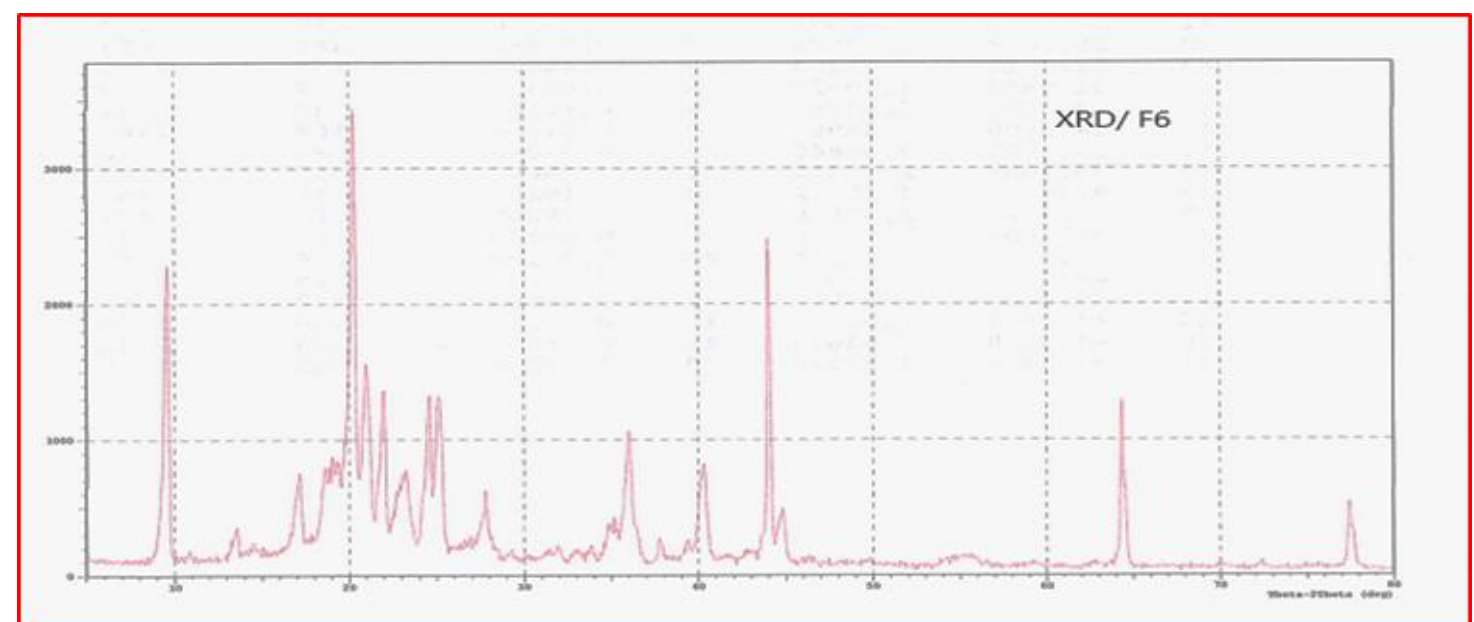

Figure 15. XRD of pure ITZ.

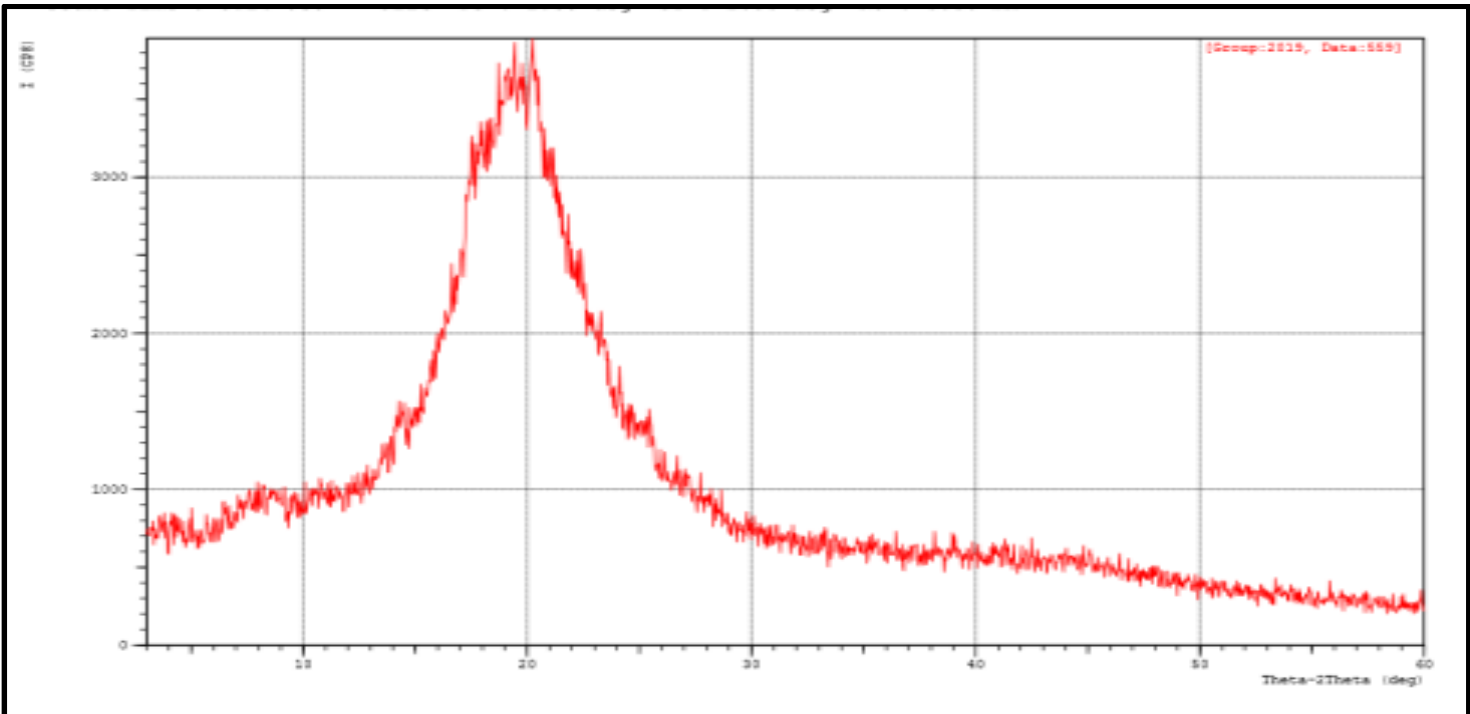

Figure 16.XRD of ITZ selected formula (F16)

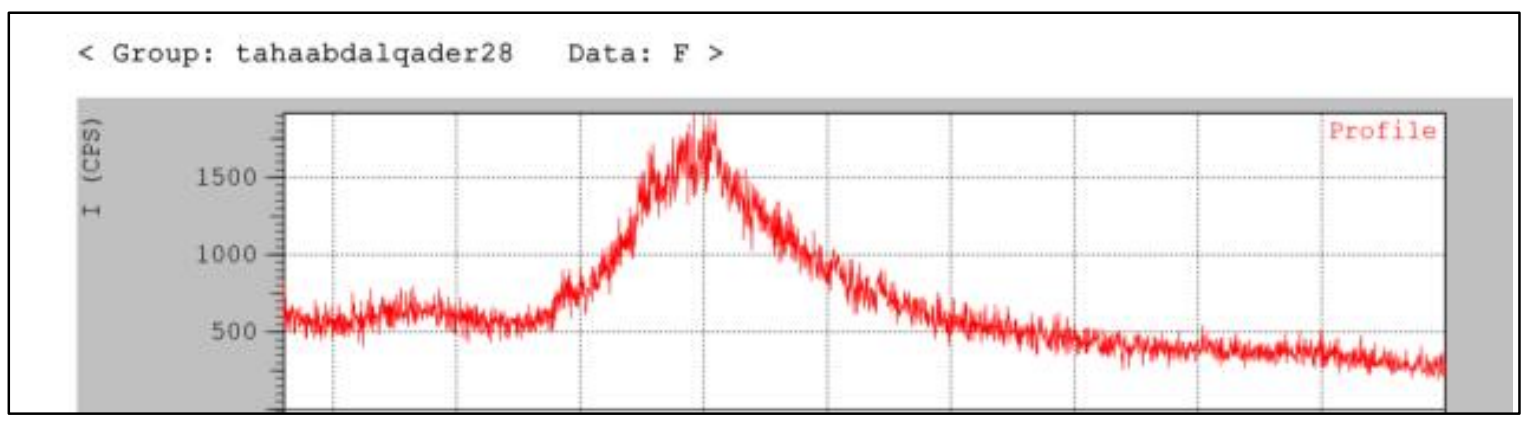

Figure 17. XRD of ITZ best pH-dependent formula ( F7)

\section{Conclusion}

Dual coating solvent evaporation method was successfully used to produce relatively $\mathrm{pH}$-independent ITZ floating microparticles by using the $\mathrm{pH}$-independent water-soluble polymer(HPMC15 cps) that provided relatively $\mathrm{pH}$-independent solubility of ITZ with a hydrophobic polymer (EC) and safflower oil that provided bouncy.
Different parameters, such as HPMC 15cps versus EC concentration, various vegetable oil including, safflower oil volume, stirring speed, oil to water ratio, co solvent type, drug- to polymer ratio were investigated and optimized to produce a formula that provided both excellent bouncy for 12 hours with maximum drug release. PH-independent ITZ floating 
microparticles (F16) was significantly better than

PH-dependent ITZ floating microparticles (F7) in both bouncy per cent at 12 hours and dissolution profile at all test media of different $\mathrm{pH}$ values $(\mathrm{p}<.05)$, therefore, Dual coating solvent evaporation method is a promising method to improve $\mathrm{pH}$-dependent and solubility problems of ITZ.

\section{References}

1. Tripathi KD. Essentials of Medical Pharmacology. $6^{\text {th }}$ edition. New Delhi: Jitendar P Vij Jaypee Brothers Medical Publishers (P) Ltd; 2013.

2. George $\mathrm{M}$, Ghosh I. Identifying the correlation between drug/stabilizer properties and critical quality attributes (CQAs) of the nanosuspension formulation prepared by wet media milling technology. European Journal of Pharmaceutical Sciences. 2013;48(1-2):142-52.

3. Li M, Rouaud O, Poncelet D.Microencapsulation by solvent evaporation: State of the art for process engineering approaches.Int. J. Pharm.2008;363(1-2):26-39 .

4. Wong CY1, Al-Salami H1, Dass CR2.Microparticles, microcapsules and microspheres: A review of recent developments and prospects for oral delivery of insulin. Int $\mathbf{J}$ Pharm. 2018; 537(1-2):223-44.

5. Virginia FU, Claudia CA, Giulio PE, Roberto AV, Daniele TI, Cesarina GI, et al. Biological properties of itraconazole-SLN . Biointerface Res. Appl. Chem.2018; 8 (5): 3624 - 27.

6. Martindale(The CompleteDrug Reference) .38ed. ,2014. P-583-85.

7. Pandey S. Itraconazole nanosuspension meant for oral use: development of formulation, characterisation and in vitro comparison with some marketed formulations.DerPharmacia Lettre. 2010;2:162-71.

8. Moffat AC, Osselton MD,Widdop B Clarke's analysis of drugs and poisons. $3^{\text {rd }}$ ed. Pharmaceutical Press: London; 2004.

9. Kavitha VB, Neethu CS, Dineshkumar B, Krishnakumar K, John A. Nanosuspension formulation: An improved drug delivery system. Nanosci Nanotechnol Int J. 2014;4:1-5.

10. Bae SK, Park SK, Shim EG, Mun JH, Kim EU, Shin JG et al.Increased oral bioavailability of itraconazole and its active metabolite,7hydroxyitraconazole, when coadministered with a vitamin $\mathrm{c}$ beverage in healthy participants.J Clin. Pharm., 2011; 51:444-451
11. Shabada A, Prashanthi $\mathrm{Y}$, Reddy $\mathrm{CH}$, Vivekananda B. Formulation development and evaluation of hydrotropic solubilization based suspensions of Itraconazole. Indo American Journal of pharmaceutical sciences. 2017;4(11):4425-34.

12. Ammar HO, Ghorab MM, Mahmoud AA, Noshi SH.Formulation of risperidone in floating microparticles to alleviate its extrapyramidal side effects. Future J Pharmace Sci. 2016;2(2):43-59.

13. Grekhnyova EV, Kudryavtseva TN, Kometiani IB, Velyaev YO. Microencapsulation of furacilin as a method of creating new medicinal forms, possessing with increased biological accessibility and prolongable effect. Asian Journal of Pharmaceutics. 2017; 11 (4): S920

14. Gökbulut E, Vural I,Aşıkoğlu M,Özdemir N. Floating drug delivery system of itraconazole: Formulation, in vitro and in vivo studies. J Drug Deliv Sci Technol. 2019;49:491-501.

15. Pore YV, Shinde VR, Rao JV. Physical stabilisation of amorphous itraconazole in solid dispersions for improved dissolution profile. Journal of Applied Pharmaceutical Science. 2016;6(10):037-44.

16. Dolenc A, Govedarica B, Kocbek P, Srčič S, Kristl J. Nanosized particles of orlistat with enhanced in vitro dissolution rate and lipase inhibition. International journal of pharmaceutics. 2010;396(1-2):149-55 .

17. Jassim ZE, Hussein AA. Formulation and evaluation of clopidogrel tablet incorporating drug nanoparticles. IJPS. 2014:838-51.

18. Hendrawati TY, Rahman MIS, Nugrahani RA, Siswahyu A, Alvika Meta Sari. Microencapsulation techniques of herbal compounds for raw materials in food industry, cosmetics and pharmaceuticals [Internet]. IntechOpen. IntechOpen; 2019 [cited 2019Nov21]. Available from: https: / /www .intechopen .com / books / microencapsulation-processestechnologies - and - industrialapplications / microencapsulationtechniques-of-herbal-compounds forraw- materials - in - food - industry cosmetics-and-p.

19. Jelvehgari M, Nokhodchi A, Rezapour M, Valizadeh4 H.Effect of Formulation and processing variables on the characteristics of tolmetin microspheres prepared by double emulsion solvent diffusion method.Indian J Pharm Sci. 2010; 72(1): 72-78. 
20. Jelvehgari M, Barar J, Nokhodchi ,A,Shadrou A, Valizadeh H.Effects of process variables on micrometric properties and drug release of nondegradable microparticles.Adv Pharm Bull.;2011; 1(1): 18-20-Rathod UC, Patel AK, Shah DA.Statistical Evaluation and optimization of influence of stirring speed and polymer concentration on hollow microspheres of diltiazem $\mathrm{HCl}$. Der Pharmacia Lettre, 2012, 4 (3):972-978.

21. Dhakar RC, Maurya SD, Sagar BP, Bhagat S, Prajapati SK, Jain CP.variables Influencing the drug entrapment efficiency of microspheres: a pharmaceutical review. Der Pharmacia Lettre, 2010, 2(5): 102-116.

22. Wo2001085135a1 - Pharmaceutical composition containing itraconazole with gastric pH-Independently Improved Solubility and preparation method thereof [Internet]. Google Patents. Google; [cited 2019Oct25]. Available from: https://patents.google.com/patent/WO2 001085135A1/en.

23. Abbas HK, Wais FM, Abood AN. Preparation and evaluation of ketoprofen nanosuspension using solvent evaporation technique. Iraqi Journal of Pharmaceutical Sciences .2017; 25(4): 41-55.

24. Devara RA, Habibudin MO, Aukunuru JI. Enhancement of dissolution rate of poorly soluble drugs itraconazole by nanosuspension technology: its preparation and evaluation studies.
Asian J Pharm Clin Res.2018; 11( 4): 414-421.

25. Ferreira PC1, Guimarães de Lima CS 2 , Noronha LL 1, Moraes MC2, Silva FC 2, Viçosa AL 3, Futuro DO1 and Ferreira VF.Development of a Method for the quantification of clotrimazole and itraconazole and study of their stability in a new microemulsion for the treatment of sporotrichosis. molecules .2019;24 (33) :1-15

26. Pore YV, Shinde VR, Rao J. Physical stabilisation of amorphous itraconazole in solid dispersion for improvement of dissolution profile. J Appl. Pharm. Sci.2016;6 (10): 037-044.re write references according

27. University of Tartu Institue of chemistry. Database of ATR-FT-IR spectra of various materials [Internet].2015; [cited 2019Nov22]. Available from: http://lisa.chem.ut.ee/IR_spectra/paint/ binders/stand-oil-safflower/.

28. Ahuja $M$, Verma $P$, Bhatia $M$. Preparation and evaluation of chitosanitraconazole coprecipitated nanosuspension for ocular delivery. Journal of Experimental Nanoscience. 2015;10(3):209.

29. Vyas PR, Patel KJ. Enhancement of solubility of Itraconazole using novel liquisolid technique. Pharma Science Monitor. 2015;6(2).269-286.

30. Wei Y, Ling Y, Su M, Qin L, Zhang J, Gao Y, Shuai Q. Characterization and stability of amorphous tadalafil and four crystalline polymorphs. Chem Pharm Bull. 2018;66(12):1114-1121.

Baghdad Iraqi Journal Pharmaceutical Sciences by bijps is licensed under a Creative Commons Attribution 4.0 International License. Copyrights@ 2015 College of Pharmacy - University of Baghdad. 